\title{
LA UTILIZACIÓN DE LA JURISPRUDENCIA CONSTITUCIONAL EXTRANJERA POR EL CONSEJO CONSTITUCIONAL FRANCÉS'
}

\author{
The use of foreign constitutional jurisprudence by the french \\ constitutional council
}

\author{
Elice Carpentier ${ }^{2}$ \\ Maître de conférences de Derecho Público \\ Universidad Paul Cézanne \\ (Aix-Marseille III, Francia) \\ carpentierelise@hotmail.fr
}

RESUMEN: El artículo analiza la aparente insensibilidad del Consejo Constitucional francés por la jurisprudencia constitucional extranjera, analizando los obstáculos coyunturales y estructurales que se presentan. Asimismo, se analiza la creciente permeabilidad del Consejo Constitucional por la jurisprudencia constitucional extranjera, utilizando las técnicas propias de ella y las soluciones adoptadas por referencia a dicha jurisprudencia extranjera, realizando algunas consideraciones finales sobre la materia.

PALABRAS CLAVE: Consejo Constitucional francés; uso de la jurisprudencia constitucional extranjera.

ABSTRACT: This article examines the apparent insensitivity of the French Constitutional Council by the foreign constitutional law, analyzing the economic and structural barriers that arise. It also examines the increasing permeability of the Constitutional Council for the foreign constitutional jurisprudence, using her own techniques and methods adopted by reference to the foreign case law, making some final thoughts on the matter.

KEY WORDS: French Constitutional Council; the use of the foreign constitutional jurisprudence.

1 Las principales ideas expuestas y ampliadas en este artículo fueron presentadas al X Congreso iberoamericano de derecho constitucional (Mesa 1: Jurisdicción constitucional - Utilización de jurisprudencia extranjera en las Cortes y Tribunales Constitucionales) que tuvo lugar en Lima (Perú) del 16 al 19 de septiembre de 2009. Recibido el artículo el 2 de octubre de 2009 y aprobado el 22 de octubre de 2009.

2 Miembro del Instituto Louis Favoreu y de la Asociación Francesa de Derecho Constitucional. 


\section{INTRODUCCIÓN (UN TEMA QUE CARECE DE OBJETO, PERO SOLO EN APARIENCIA)}

El tema de este estudio podría legítimamente dejar perplejo a todo observador bastante lejano de la jurisprudencia constitucional francesa. A primera vista, en efecto, se trata, simplemente, de un asunto que carece de objeto.

De hecho, no se encuentra en ninguna de las decisiones del Consejo Constitucional desde su creación en 1958 la menor mención a una sentencia de cualquier jurisdicción constitucional extranjera. ${ }^{3}$

Sin embargo, sería excesivo decir que el Consejo Constitucional es absolutamente indiferente a la jurisprudencia de sus homólogos extranjeros. Al contrario, un examen atento de sus trabajos demuestra una cierta permeabilidad al derecho comparado del contencioso constitucional francés.

Sobre estos dos aspectos me ocuparé sucesivamente, examinando primero la aparente insensibilidad (I) y luego la permeabilidad creciente (II) del Consejo Constitucional frente a la jurisprudencia constitucional extranjera.

\subsection{La aparente insensibilidad del Consejo Constitucional a la jurisprudencia constitucional extranjera}

La aparente indiferencia del Consejo Constitucional francés a la jurisprudencia constitucional extranjera resulta de la combinación de una serie de factores, u obstáculos, que son de orden coyuntural (A) o estructural (B).

\section{A. Los obstáculos coyunturales}

Estos obstáculos son tres. En general, todos ellos tienen en común la carencia de conocimiento de la jurisprudencia extranjera y -como lo sugiere su carácter coyuntural- una cierta relatividad.

En primer lugar, se ha observado que la información disponible de la jurisprudencia constitucional extranjera no se encuentra sistemáticamente organizada. En palabras del presidente Genevois, "hay fallos" y "por tanto, es preciso avanzar en adquirir un mejor conocimiento de la jurisprudencia de las jurisdicciones extranjeras". ${ }^{4}$

3 Las decisiones del Consejo Constitucional -y especialmente las citadas en este artículo- son accesibles en su sitio web (http://www.conseil-constitutionnel.fr/).

4 Genevols, B. (2006). "L'inspiration réciproque des jurisprudences des juridictions suprêmes nationales et internationales en matière de droits fondamentaux”, en Diversité des systèmes juridiques et inspiration réciproque des juges, Actes du colloque du Cercle France-Amériques du 24 octobre 2006, Cycle Attractivité économique du droit, LPA 2008, $\mathrm{n}^{\circ} 112$, p. 15. El autor señala que el Consejo Constitucional ha admitido la conformidad con la Constitución de una pena "privativa de nacionalidad" (Décisión 
Esta constatación no carece de fundamento, pero debe ser relativizada a la vista de los esfuerzos llevados a cabo para mejorar los sistemas de difusión de la jurisprudencia constitucional extranjera en el seno de instituciones como la Comisión de Venecia (con su base de datos "CODICES"5), la Asociación de Tribunales Constitucionales que comparten el uso del francés (ACCPUF) o la Asociación de Tribunales Constitucionales europeos. Cabe señalar, también, que aunque el Consejo Constitucional francés no se haya dotado de un órgano interno especializado en el derecho comparado (como sí lo tiene el Tribunal Constitucional italiano), él intercambia sus repertorios de jurisprudencia con una cincuentena de Tribunales constitucionales y multiplica los encuentros y programas comunes de investigación con sus homólogos extranjeros. Además, su Servicio de Documentación consulta ahora con regularidad las páginas de internet de las jurisdicciones constitucionales vecinas, así como algunas revistas de derecho constitucional extranjero.

En segundo lugar, es preciso admitir que el derecho constitucional comparado se ha desarrollado de manera relativamente tardía en Francia. No es hasta los años ochenta cuando se ha impulsado su tratamiento por el decano Louis Favoreu en el seno de su grupo de investigación, ${ }^{6}$ especialmente con la organización de Mesas Redondas Internacionales de justicia constitucional y la publicación del Annuaire International de Justice Constitutionnelle (AIJC) cada año desde 1985. Ahora bien, es claro que el juez no está vinculado por la doctrina, pero ésta puede influenciar sus métodos de trabajo y sus modos de argumentar. Habría, por tanto, mayores posibilidades de que el juez constitucional recurriera al derecho comparado si la literatura pusiera a su disposición los medios para hacerlo.

No obstante, sobre este punto también, es observable que se ha avanzado. De manera general, no se concibe más, en la actualidad, hacer derecho constitucional sin hacer derecho comparado (numerosas tesis doctorales sostenidas hoy en día dedican un gran espacio al derecho comparado). Mas específicamente, es posible señalar la publicación, recientemente, de una obra consagrada a las Grandes décisions des Cours constitutionnelles européennes, examinando las soluciones proporcionadas por las diversas jurisdicciones constitucionales europeas a algunos problemas jurídicos comunes. ${ }^{7}$

En tercer lugar, por fuerza hay que constatar que las partes en el proceso constitucional invocan raramente la jurisprudencia constitucional extranjera y que, cuando lo hacen, las referencias no son siempre pertinentes. ${ }^{8}$

$\mathrm{n}^{\circ}$ 96-377 DC de 16 de julio de 1996) ignorando la posición del Tribunal Supremo de los Estados Unidos que había considerado anteriormente una pena así como inconstitucional.

5 Base de datos que consiste en un tesauro y reglas de indexación comunes de las decisiones y las Constituciones del conjunto de países miembros de la Comisión de Venecia y de la ACCPUF.

6 El "GERJC" - Grupo de Estudios e Investigaciones sobre la Justicia Constitucional-, que en adelante lleva su nombre: "ILF" - Instituto Louis Favoreu.

7 Bon P. y. Maus, D. (2008) Grandes décisions des Cours constitutionnelles européennes. (Paris, Dalloz).

8 Por ejemplo, la invocación, en la demanda planteada por los diputados contra la institución de las penas "plancher", de una decisión del Tribunal Supremo de los Estados Unidos (del 12 de enero de 2005) respecto de que la aplicación obligatoria de las directivas federales lesionaba el derecho a ser 
Aunque tampoco este elemento es determinante porque el procedimiento ante el Consejo Constitucional es en gran medida inquisitorial, de modo que nunca se limita, ni en sus investigaciones ni en sus razonamientos, por los argumentos de los demandantes.

Entonces, estos primeros obstáculos están impregnados de una cierta relatividad, pero existen causas más profundas que explican la aparente indiferencia del juez constitucional francés respecto de la jurisprudencia constitucional extranjera.

\section{B. Los obstáculos estructurales}

La primera barrera estructural a la utilización de la jurisprudencia extranjera por el Consejo Constitucional es la adscripción francesa a la tradición romana-germánica que privilegia el derecho escrito y niega, en principio, toda normatividad a la jurisprudencia. Ahora bien, si esta negativa se refiere al poder judicial propio, a fortiori se extiende también a la jurisprudencia extranjera. Por el contrario, en los sistemas de common law "la investigación y cita de los precedentes forma parte de la cultura fundamental" y el juez motiva sus decisiones "no tanto, o no solamente, para justificarlas, sino, sobre todo, porque la motivación representa un momento en la creación jurisprudencial del derecho". ${ }^{10}$

Sin embargo, hace falta reconocer que la pureza de los sistemas jurídicos existe más en el mundo literario que en el real. De hecho, a la jurisprudencia se la reconoce hoy una cierta normatividad en Francia, fenómeno reforzado por la sumisión al derecho europeo, edificado sobre el modelo del common law. Este obstáculo no es, pues, insalvable en absoluto.

El segundo obstáculo estructural descansa sobre el modo de funcionamiento del Consejo Constitucional francés. Ciertamente, su pertenencia al modelo kelseniano y europeo de justicia constitucional no es en sí mismo determinante, como demuestra la experiencia española, donde el Tribunal Constitucional se refiere frecuentemente a la jurisprudencia de sus homólogos extranjeros. ${ }^{11}$ Pero el Consejo Constitucional conoce modos de funcionamiento bastante originales, que le distinguen de un buen número de tribunales constitucionales europeos. Aquí sobresalen dos especificidades.

Por encima de todo, el control de constitucionalidad ejercitado por el juez constitucional francés es todavía un control a priori que debe realizarse en un plazo particu-

juzgado por un jurado previsto por la Constitución (Décision n 2007-554 CD de 9 de agosto de 2007, Loi renforçant la lutte contra la récidive des majeurs et des mineurs: la decisión invocada no es mencionada en el dossier documental establecido por el Consejo Constitucional).

9 Maus, D. (2009). "Le recours aux précédents étrangers et le dialogue des Cours constitutionnelles", Comunicación en la Conferencia mundial de justicia constitucional, Le Cap, 22-24 de enero de 2009, p. 11.

10 Ponthoreau, M.-C. (2005). "Le recours aux 'l'argument de droit comparé' par le juge constitutionnel Quelques problèmes théoriques et techniques”, en F. Melin-Soucramanien (dir.), L'interprétation constitutionnelle, (Paris, Dalloz), p. 180.

11 Ponthoreau, M.-C. (2005), p. 181. 
larmente breve (un mes en principio y ocho días si el Gobierno declara la urgencia). Esta constricción limita naturalmente las posibilidades de que el juez extienda sus investigaciones a la jurisprudencia constitucional extranjera.

No obstante, el Consejo Constitucional suele empezar sus trabajos en la mayoría de ocasiones antes de que se plantee la demanda (cuando los trabajos parlamentarios le permiten deducir que tendrá que conocer del asunto). Y además, se está instaurando en Francia una vía de control de constitucionalidad de las leyes a posteriori, con lo cual la restricción temporal vendrá a menos (tres meses según la ley orgánica, hoy en curso de adopción).

Por otro lado, el Consejo Constitucional tiende por lo general (siguiendo probablemente el ejemplo del Consejo de Estado) a las motivaciones muy concisas, que no se acompañan de eventuales opiniones discrepantes de los jueces. Ahora bien, como ha subrayado M.-C. Ponthoreau, "un estilo judicial discursivo, narrativo y analítico apoyado sobre la práctica de opiniones individuales de los jueces es netamente más propicio al recurso al derecho extranjero para interpretar la Constitución porque considera el proceso interpretativo y decisorio como un intercambio de argumentos llegando a una decisión". ${ }^{2}$ De hecho, parece que sólo los tribunales de este tipo se refieren de modo explícito y reiterado al argumento de derecho comparado, ya sea de forma decisiva o simplemente aclaratoria. ${ }^{13}$

Sin embargo, se constata desde hace tiempo un cambio de "estilo" en la redacción de sus decisiones por parte del Consejo Constitucional. Aunque no permiten conocer las discusiones que tienen lugar en el seno de la jurisdicción, las decisiones son hoy bastante más largas y argumentadas que antes. Además, las investigaciones y reflexiones que las preceden son objeto de una cierta publicidad por medio de los dossiers documentales y comentarios sistemáticamente publicados en la página web del Consejo, ${ }^{14}$ así como de los archivos del Consejo Constitucional, recientemente abiertos a la consulta del público (para el periodo 1958-1983). ${ }^{15}$

En fin, para terminar con las causas de la "autarquía” del juez constitucional francés, se puede sostener que el recurso al derecho comparado es más frecuente en los Estados en trance de transición democrática. La utilización de la jurisprudencia constitucional extranjera puede ser un medio para el juez constitucional de compensar la ausencia de precedentes propios y de legitimar sus decisiones, apoyándose en las de tribunales más antiguos, de democracias estables, y donde no se contesta su autoridad. Este fenómeno se puede verificar en Sudáfrica, ${ }^{16}$ donde el art. 39 (1) de la Constitución invita expresa-

12 Ponthoreau, M.-C. (2005), pp. $168 \mathrm{~s}$.

13 Ponthoreau, M.-C. (2005), p. 181.

14 http://www.conseil-constitutionnel.fr/

15 Cf. la presentación y el análisis de las grandes deliberaciones en la obra de B. MATHIEU, J.-P. MACHELON, F. Mélin-Soucramanien, D. Rousseau et X. Philippe, (2009). Les grandes délibérations du Conseil constitutionnel, (Paris, Dalloz).

16 Cf. En particular la decisión sobre la pena de muerte de 1995, State v. Markwanyane. 
mente a las jurisdicciones nacionales a inspirarse en el derecho extranjero para interpretar el Bill of Rights, así como en las jóvenes democracias de Europa central y oriental (donde los jueces constitucionales han además sido en muchas ocasiones formados en el extranjero, lo que favorece el reflejo y la reflexión comparatistas).

Es, sin embargo, claro que el derecho comparado no presenta interés sólo para los tribunales constitucionales noveles, como lo demuestra, a pesar de su antigüedad y legitimidad, la sensibilidad creciente del Consejo Constitucional hacia la jurisprudencia constitucional extranjera.

\section{LA CRECIENTE PERMEABILIDAD DEL CONSEJO CONSTITUCIONAL HACIA LA JURISPRUDENCIA CONSTITUCIONAL EXTRANJERA}

Como se ha indicado, el Consejo Constitucional jamás ha citado jurisprudencia constitucional extranjera en sus decisiones. ${ }^{17}$ Sin embargo, incontestablemente se ha inspirado en ella a veces, sobre todo en el periodo reciente. ${ }^{18}$ De manera general, como ha subrayado el juez O. Dutheillet de Lamothe en el Congreso Mundial de Derecho Constitucional de $2004,{ }^{19}$ la toma en consideración de la jurisprudencia constitucional extranjera por el juez constitucional francés se manifiesta tanto en las técnicas de control (A) cuanto en el fondo de ese mismo control, es decir, en las soluciones adoptadas (B).

\section{A. Las técnicas de control inspiradas en la jurisprudencia constitucional extranjera}

El Consejo Constitucional se ha inspirado en la jurisprudencia de sus homólogos extranjeros para afinar sus técnicas de control de constitucionalidad al menos de tres maneras.

17 Pero sí se ha referido una vez a una sentencia del Tribunal Europeo de Derechos Humanos (Décisión $\mathrm{n}^{\circ}$ 2004-505 DC de 19 de noviembre de 2004, Traité établissant une Constitution pour l'Europe, citando una sentencia de la CEDH de 29 de junio de 2004), y otra vez a una sentencia del Tribunal de Justicia de las Comunidades Europeas (Décision n 2005-531 DC de 29 de diciembre de 2005, Loi de finances rectificative pour 2005, citando en el cuerpo de su decisión una sentencia de la CJCE de 12 de septiembre de 2000). Si la toma en consideración, más o menos explícita pero inevitable, de las jurisprudencias europeas por el Consejo Constitucional puede o no suponer una importación indirecta de la jurisprudencia constitucional extranjera en las que aquéllas se inspiran a veces, es un fenómeno excesivamente complejo y marginal para que pueda ser abordado por esta Comunicación.

18 Destaca esto esencialmente de los documentos de trabajo de los jueces colocados en el sitio Internet del Consejo a partir de los años ochenta (en particular, de los informes documentales elaborados en el curso de la instrucción de las demandas que se distribuyen en audiencia al conjunto de los jueces constitucionales) y de los comentarios redactados por los servicios del Consejo tal como se vienen publicando en los Cahiers du Conseil Constitutionnel desde 1996 (también disponibles en el sitio web del Consejo). La consulta de los archivos del Consejo Constitucional, abiertos para el periodo 19581983, permite encontrar algunas referencias a la jurisprudencia constitucional extranjera en los debates en el seno de la jurisdicción, pero la doctrina está de acuerdo sobre la relativa novedad de este fenómeno (cf. sobre todo los artículos citados de D. Maus, M.-C. Ponthoreau y F. Jacquelot).

19 "Le constitutionnalisme comparatif dans la pratique du Conseil Constitutionnel", intervención ante el XVI Congreso Mundial de Derecho Constitucional, Santiago de Chile, 16 de enero de 2004, disponible en el sitio web del Consejo Constitucional. 
Primero, como ha mostrado la escuela de Aix, ${ }^{20}$ el Consejo Constitucional se ha inspirado directamente en el Tribunal Constitucional italiano para acuñar su técnica de las reservas de interpretación. Esta técnica aparece de modo muy temprano en la jurisprudencia del Consejo Constitucional ${ }^{21}$ y es sin duda inherente al propio ejercicio del control de constitucionalidad, ya que el juez no puede dejarse encerrar en la elección binaria entre la censura de la ley o el rechazo de la demanda. Pero nunca se ha impugnado que, para su aplicación, el juez constitucional francés se inspiró en la Consulta italiana.

Del mismo modo, el Consejo Constitucional parece inspirarse en la "doctrina" italiana del derecho vivo. Esta doctrina consiste, en substancia, para el Tribunal Constitucional italiano, en no deducir una interpretación autónoma de las disposiciones legislativas que debe controlar cuando éstas ya han sido interpretadas por las jurisdicciones ordinarias y otras autoridades públicas. El Tribunal adopta entonces esta interpretación vivante, esto es, el sentido que la ley ha adquirido durante su aplicación. Según O. Dutheillet de Lamothe, esta doctrina ejerce "una influencia creciente sobre el Consejo Constitucional francés preocupado, como el Tribunal italiano, por establecer una colaboración armoniosa con los otros Tribunales Supremos". ${ }^{22}$ De hecho, es dable pensar que esta influencia se reforzará en el futuro cuando Francia se dote de una vía de control a posteriori de constitucionalidad de las leyes, a la que la doctrina del derecho vivo se halla esencialmente ligada.

Por último, el Consejo Constitucional se ha inspirado recientemente en la jurisprudencia del Tribunal Constitucional federal alemán para precisar las exigencias inherentes al control de proporcionalidad, cada vez más presente en materia de derechos fundamentales. Así, ha precisado, siguiendo la estela del Tribunal de Karlsruhe, que para ser proporcionada, la retención de seguridad prevista por la ley sometida a su examen, debe satisfacer la triple exigencia de adecuación (debe ser apropiada y adaptada a la finalidad buscada por el legislador), de necesidad (no debe exceder lo que requiere la finalidad perseguida y este objetivo no debe poder ser conseguido por otros medios menos gravosos a la libertad) y de proporcionalidad en sentido estricto (no debe, por las cargas que crea, ser desequilibrada respecto del resultado pretendido). ${ }^{23}$ Hasta ese momento, el Consejo Constitucional no había jamás empleado los tres elementos de este test triple; sólo los había utilizado separadamente o de dos en dos.

20 Cf. L. Favoreu, “La décision de constitutionnalité”, RIDC 1986, p. 611 y T. Di MANNo, Le juge constitutionnel et la technique des décisions interprétatives en France et en Italie, Economica-PUAM, 1997, pp. 17 ss.

21 Décision $n^{\circ}$ 59-2 DC de 17, 18 y 24 de junio de 1959, Réglement de l'Assemblée Nationale (segunda decisión rendida por el Consejo Constitucional).

22 Artículo citado. F. Jacquelot subraya por su parte que el Consejo Constitucional "tiene muy en cuenta, en su reflexión, la jurisprudencia de las dos Cortes Supremas (de los órdenes de las jurisdicciones ordinarias) para exponer los principios constitucionales y también en el momento de su aplicación. No es raro que la jurisprudencia de estos tribunales supremos inspire el contenido de las reservas de interpretación formuladas por el Consejo Constitucional, incluso en las declaraciones de inconstitucionalidad".

23 Décision $\mathrm{n}^{\circ}$ 2008-562 DC de 21 de febrero de 2008, Loi relative à la rétention de sûreté et à la déclaration d'irresponsabilité pénale pour cause de trouble mental (el informe documental de la decisión se inspira en la sentencia del Tribunal Constitucional alemana de 5 de febrero de 2004). 


\section{B. Las soluciones adoptadas por referencia a la jurisprudencia constitucional extranjera}

Aunque se constata el crecimiento de la frecuencia de este fenómeno en los últimos años, los asuntos en los que el Consejo Constitucional se refiere indudablemente a la jurisprudencia constitucional extranjera para alcanzar su convicción son todavía escasos. Sería, por tanto, prematuro elaborar una teoría sobre este tema, aunque sí es posible formular algunas hipótesis.

La primera alude a los ámbitos en los que el Consejo Constitucional parece más inclinado a tomar conocimiento de la jurisprudencia constitucional extranjera. En este sentido, sobresalen dos materias: los derechos fundamentales y las relaciones del sistema de fuentes (es decir, las relaciones entre los ordenamientos jurídicos nacional y comunitario europeo).

Por lo que dice a los derechos fundamentales, el Consejo, por ejemplo, ha tenido en cuenta las posiciones adoptadas por las diferentes jurisdicciones constitucionales para resolver, por primera vez, la cuestión de si el principio de igualdad, que obliga a tratar de la misma forma a las personas que se encuentran en la misma situación, impone, simétricamente, la obligación de tratar de modo distinto a las personas que se hallan en situaciones diferentes. ${ }^{24} \mathrm{El} \mathrm{juez} \mathrm{constitucional} \mathrm{francés} \mathrm{se} \mathrm{ha} \mathrm{también} \mathrm{inspi-}$ rado manifiestamente en la jurisprudencia del Tribunal Constitucional federal alemán para validar la ley bajando la tasa del escudo fiscal a unos 50\%, ${ }^{25}$ asî́ como las leyes que crean el registro internacional francés, ${ }^{26}$ o la retención de seguridad, ${ }^{27}$ que todas plantean cuestiones de derecho constitucional sustantivo. Antes, ya se había inspirado en una decisión de su homólogo de Karlsruhe para consagrar el principio de autonomía de los profesores de Universidad. ${ }^{28}$ Y la primera decisión en la que el Consejo Constitucional ha tenido en cuenta la jurisprudencia de otros tribunales constitucionales fue la ley que autorizaba la interrupción voluntaria del embarazo. ${ }^{29}$

Este último ejemplo demuestra que el juez constitucional no es reacio al derecho comparado cuando está llamado a pronunciarse sobre las auténticas elecciones de la sociedad; al contrario, ya que el Consejo Constitucional siguió inspirándose en la jurisprudencia constitucional extranjera cuando tuvo que pronunciarse en 2001 sobre la

24 Décision $n^{\circ}$ 2003-489 DC de 29 de diciembre de 2003, Loi de finances pour 2004.

25 Décision $n^{\circ}$ 2005-530 DC de 29 de diciembre de 2005, Loi de finances pour 2006. El escudo fiscal es una medida fiscal que define una tasa máxima de imposición de los contribuyentes.

26 Décision $\mathrm{n}^{\circ}$ 2005-514 DC de 28 de abril de 2005, Loi relative à la création du registre international français.

27 Décision $n^{\circ}$ 2008-562, DC de 21 de febrero de 2008, precitada. La retención de seguridad es una medida que permite mantener en una cárcel personas que han efectuado su condena y que deberían salir pero que presentan importantes riesgos de reincidencia.

28 Décision $n^{\circ}$ 83-165 DC de 20 de enero de 1984, Loi relative á l'enseignement supérieur.

29 Décision $\mathrm{n}^{\circ}$ 74-54 DC de 15 de enero de 1975, Loi relative à l'interruption volontaire de grossesse. 
ampliación de 10 a 12 semanas del plazo en el que una mujer puede, bajo ciertas condiciones, decidir interrumpir su embarazo. ${ }^{30}$

Con carácter general, los casos en los que el Consejo Constitucional parece más dispuesto a conocer las tesis adoptadas por sus homólogos extranjeros son los relativos, o a las nuevas cuestiones planteadas por los derechos fundamentales, o a las antiguas pero ligadas a una probable evolución interpretativa derivada de un cambio de la visión y costumbres sociales.

Respecto de las relaciones entre sistemas normativos, no hay duda de que el Consejo Constitucional presta creciente atención a la jurisprudencia constitucional de los Estados miembros de la Unión y que no se pronuncia sobre un Tratado europeo sin haber antes examinado las decisiones de los tribunales constitucionales extranjeros sobre ese mismo Tratado o sobre sus precedentes.

Por ejemplo, el informe documental de la decisión sobre el Tratado constitucional europeo tiene en cuenta la decisión adoptada por el Tribunal Constitucional alemán sobre el Tratado de Maastricht. ${ }^{31} \mathrm{Y}$ si las decisiones relativas al control de las leyes de transposición de las directivas no han tomado en consideración expresa a la jurisprudencia constitucional extranjera, no hay duda de que se inspiran en ella. ${ }^{32}$

Fuera del contencioso mismo, parece que la cuestión de las relaciones entre la Constitución y las normas europeas se aborda sistemáticamente en los encuentros entre el Consejo Constitucional y sus homólogos europeos.

La segunda hipótesis que puede ser formulada concierne a los países a los que se refiere el Consejo Constitucional en sus investigaciones comparatistas. Sobre este punto, vemos que el Consejo se refiere principalmente a la jurisprudencia de los Tribunales alemán (por el que manifiesta una clara preferencia), italiano y español, así como a los trabajos del Tribunal Supremo de los Estados Unidos.

Atiende, pues, a jurisdicciones constitucionales más antiguas que él (con la excepción de España) y próximas geográficamente (con la excepción de Estados Unidos) y/ o culturalmente con Francia. Esto no es original. La importancia de la antigüedad y de

30 Décision $\mathrm{n}^{\circ}$ 2001-446 DC de 27 de junio, Loi relative à l'interruption volontaire de grossesse et à la contraception.

31 Décision $\mathrm{n}^{\circ}$ 2004-505 DC de 19 de noviembre de 2004, Traité établissant une Constitution pour l'Europe (traducida en inglés, español y alemán en el sitio web del Consejo Constitucional, y comentada en la Revista española de derecho europeo, 2005 (14), pp. 257-281 -comentario de L. Burgorgue-Larsen titulado "El Tratado por el que se establece una Constitución para Europa ante el Consejo constitucional francés: entre lo novedoso y lo ortodoxo, Francia resiste").

32 Cf. sobre todo la primera decisión sobre la cuestión, $\mathrm{n}^{\circ}$ 2004-496 DC Loi pour la confiance dans l'économie numérique, que parece hacerse eco de las decisiones "Solange" I, II y III del Tribunal Constitucional de Karlsruhe (de 29 de mayo de 1974, 22 de octubre de 1986 y 7 de junio de 2000), y de la decisión "Fragd" de la Consulta italiana del 13 de abril de 1989. 
la proximidad cultural, histórica, política y constitucional (a menudo vinculada a la proximidad geográfica) ya han sido observadas. Por una parte, como lo hemos dicho supra a propósito de los Estados en trance de transición democrática, ${ }^{33}$ las jurisdicciones constitucionales que utilizan el derecho comparado tienen tendencia a referirse a otras que tengan una cierta "experiencia", sólidamente instaladas en su paisaje institucional y sin dudas sobre su legitimidad. Por otra parte, es claro que no puede compararse aquello que no comparte valores comunes y menos cuando no se conoce con exactitud el contexto de la jurisprudencia. ${ }^{34} \mathrm{Al}$ contrario, la comunidad lingüística no parece determinante. ${ }^{35}$

Por último, la preferencia observada hacia el Tribunal de Karlsruhe se debe probablemente, al menos en parte, a la "admiración" que Francia (como otros Estados) tiene al Derecho Constitucional alemán. Alemania ha sido siempre un lugar de alta reflexión constitucionalista.

La tercera y última hipótesis invoca la razón y por tanto el objeto (la finalidad) del recurso al derecho comparado. Desde este punto de vista, es difícil pronunciarse porque si es claro que el Consejo Constitucional francés no utiliza el derecho comparado con fines simplemente retóricos, o de modo puramente "decorativo", ${ }^{36}$ no se puede todavía sostener que constituye un auténtico método de interpretación. De hecho, el derecho comparado parece cumplir tres grandes funciones en la jurisprudencia del juez constitucional, una de carácter general y dos mas especiales.

La primera función - de carácter general- es una función heurística, en la medida en que el conocimiento de las experiencias extranjeras permite al Consejo tener una visión completa de las respuestas posibles a un problema jurídico determinado. Esta función del derecho comparado es bastante perceptible en los trabajos que han precedido la decisión de 1975 sobre interrupción voluntaria del embarazo ${ }^{37}$ o la decisión de 2003 sobre las implicaciones del principio de igualdad. ${ }^{38}$

La segunda función es una función de justificación y más precisamente de legitimación de las decisiones adoptadas en materia de derechos fundamentales, sobre todo cuando las interpretaciones que las fundan no se deducen de modo evidente de la lectura de los textos. Tal es el caso cuando el Consejo debe pronunciarse sobre una

33 Cf. supra I, B, in fine.

34 La "descontextualización" es un riesgo inherente al derecho comparado a menudo evocado por la doctrina. Cf. sobre todo M.-C. Ponthoreau, que subraya la complejidad del trabajo de contextualización, que afecta a aspectos jurídicos tanto como a otros extrajurídicos, especialmente ideológicos, socio-económicos, históricos y lingüísticos (artículo precitado, en F. MeLIN-Soucramanien (dir.), (2005), L'interprétation constitutionnelle, (París,Dalloz), p. 179).

35 Sin embargo, hay que reconocer que las jurisdicciones constitucionales traducen cada vez más sus decisiones (principalmente al inglés, pero a veces también en francés).

36 Ponthoreau, M.-C. "La droit comparé en question(s) -Entre pragmatisme et outil épistémologique", RIDC $1 / 2005$, p. 9.

37 Décision $n^{\circ}$ 74-54 DC de 15 de enero de 1975, precitada.

38 Décision $n^{\circ}$ 2003-489 DC de 29 de diciembre de 2003, precitada. 
cuestión nueva o controvertida: el recurso al derecho comparado permite a menudo mostrar que Francia no protege menos los derechos fundamentales que sus vecinos (geográficos o culturales). Se puede citar el ejemplo de la interrupción voluntaria del embarazo, sobre lo que las investigaciones comparatistas del Consejo Constitucional mostraban en 1975 que la ley en examen constituía una suerte de compromiso -o de justo equilibrio- entre las diferencias legislaciones existentes en la época, y en 2001 que un cierto número de países habían adoptado progresivamente la equilibrada posición francesa. ${ }^{39}$ Se puede también evocar los ejemplos del principio de igualdad, sobre el que el Consejo Constitucional ha adoptado la interpretación más "igualitarista”, ${ }^{40}$ de la retención administrativa, a propósito de la que el Consejo ha mostrado que Francia se sitúa en un punto medio de plazos de retención aplicables en Europa, ${ }^{41}$ del escudo fiscal, donde el Consejo Constitucional ha observado que se trata de una exigencia constitucional en Alemania, ${ }^{42}$ o de la retención de seguridad, sobre la que el Consejo Constitucional ha sugerido que es más protector que su homólogo alemán. ${ }^{43}$ Tal es igualmente el caso cuando el Consejo acuña un nuevo principio constitucional no expresamente previsto por la Constitución, como ha sido el caso del principio fundamental reconocido por las leyes de la República de la independencia de los profesores de Universidad, antes consagrado por el Tribunal de Karlsruhe. ${ }^{44}$

La tercera función de la utilización de la jurisprudencia constitucional extranjera por el Consejo Constitucional concierne más específicamente a las decisiones relativas a los textos europeos. En estos supuestos, en efecto, el derecho comparado juega una especie de función "defensiva": el alineamiento del Consejo con las decisiones adoptadas antes por sus homólogos europeos persigue no crear entre ellos divergencias que debiliten "la causa constitucional" en beneficio del Derecho comunitario europeo. Las jurisdicciones constitucionales europeas tienen siempre presente la idea de que resistirán mejor a la vocación holista del derecho comunitario europeo, a su voluntad de prevalecer sobre las Constitucionales nacionales, si forman "bloque" o "frente común", mejor que si se muestran divididas a la hora de confrontar las cuestiones fundamentales a las que son Ilamadas cada vez más frontal y frecuentemente.

\section{CONCLUSIÓN (VALORACIÓN DEL FENÓMENO OBSERVADO)}

¿Qué pensar de esta política del Consejo Constitucional sobre la toma en consideración de la jurisprudencia constitucional extranjera? Es el problema al que intentaré

Décisions $n^{\circ}$ 74-54 DC de 15 de enero de 1975 y n 2001-446 DC de 27 de junio de 2001, precitadas.

40 Décision $n^{\circ}$ 2003-489 DC de 29 de diciembre de 2003, precitada.

41 Décision $n^{\circ}$ 2003-484 DC de 20 de noviembre de 2003, precitada.

42 Décision $n^{\circ}$ 2005-530 DC de 29 de diciembre de 2005, precitada.

43 Décision $n^{\circ}$ 2008-562 DC de 21 de febrero de 2008, precitada.

44 Décision n ${ }^{\circ}$ 83-165 DC de 20 de enero de 1984, precitada. Lo mismo podría decirse de las técnicas de control de constitucionalidad, cuando el Consejo afina su control, como ocurre al importar la novedosa técnica del control de proporcionalidad desde el Tribunal Constitucional federal alemán (decisión $n^{\circ} 2008$ 562 DC de 21 de febrero de 2008, precitada). 
responder como conclusión de este artículo, dentro del marco general de las grandes reflexiones que tuvieron lugar antes sobre el asunto. En efecto, el recurso a la jurisprudencia constitucional extranjera por el juez constitucional ha provocado un debate teórico fuerte e interesante entre partidarios y detractores, del que conviene recordar los principales argumentos esgrimidos a fin de tomar posición.

A la cabeza de los partidarios se halla el profesor Häberle, para quien el recurso al derecho comparado debe ocupar un lugar entre los métodos de interpretación de la Constitución, a continuación de los cuatro criterios clásicos descritos por F.C. von Savigny en 1840 (gramatical, lógico, histórico y sistemático). Esto sería una consecuencia de la evolución hacia un "Estado constitucional cooperativo", resultado inevitable de los procesos de integración europea y de internacionalización de los derechos del hombre. ${ }^{45} \mathrm{El}$ comparativismo sería un instrumento indispensable del progreso de la cultura constitucional.

A este argumento Ernst Wolfgang Böckenförde objeta que la utilización del derecho extranjero por el juez constitucional conduce a una disolución completa de la normatividad de la Constitución. Ciertamente, la tesis del profesor Häberle se inspira en una concepción iconoclasta y vanguardista según la cual existiría un derecho constitucional europeo común (o un derecho constitucional europeo/atlántico común), al que estarían sometidas las Constituciones nacionales. Esto quizá pueda ser verdad en el futuro, pero no lo es en absoluto actualmente. ${ }^{46}$ Se puede apreciar, incluso, en la tesis de Häberle una suerte de aporía. Según él, en efecto, el juez no sería sino el receptáculo de un consenso ya existente sobre el contenido y la interpretación de la Constitución. Pero cuando surge un conflicto alrededor de este contenido, es claro que este consenso sobre los valores constitucionales no existe. Finalmente, se puede preguntar, con el Juez Scalia, si el derecho comparado no tiene más su lugar en el proceso político de elaboración o de modificación de la Constitución que en el momento de su interpretación por el juez, ${ }^{47}$ sobre todo en los sistemas romano-germánicos, donde la actividad está particularmente restringida y la subjetividad es bastante menos permitida.

Seguramente, pero también es seguro que el conocimiento del derecho extranjero permite, como ha subrayado el Juez Breyer en su célebre controversia con el Juez Scalia, "obtener un enfoque empírico sobre las consecuencias resultantes de soluciones diferentes a un problema común" $48 \mathrm{y}$, siguiendo el razonamiento del profesor

45 Häberle, P. (1994). "El concepto de derechos fundamentales", en Problemas actuales de los derechos fundamentales, (Madrid, Universidad Carlos III de Madrid, Ed. José María Sauca), pp. 109 s.

46 Böckenförde, E.W. (2000). Le droit, l'Etat et la Constitution démocratique (textos traducidos y comentados por O. Jouanjan), (Bruselas-París, Bruylant-LGDJ), pp. 235 s. Esta crítica es retomada por O. Jouanjan para quien si el juez constitucional utiliza el derecho extranjero "la Constitución se convierte, en el mejor de los casos, en l'auberge espagnole, y en el peor, en el tonel de las Danaides".

47 Opinión del Tribunal por el Juez Scalia en la Sentencia Printz v. United States (521 US 898, 1997).

48 Opinión disidente del Juez Breyer en la Sentencia Printz, precitada. 
Slaughter, "abordar de manera más creativa o con mayor perspicacia" un problema jurídico nuevo o particularmente controvertido. ${ }^{49}$

En conclusión, muestro mis reservas a la utilización por el Consejo Constitucional francés de la jurisprudencia extranjera como argumento de autoridad, en razón de las concepciones de la Constitución y de la función del juez que eso presupondría. Pero soy partidaria de utilizar tal jurisprudencia con finalidades documentales, lo que no es sin hacer pesar algunas responsabilidades sobre la doctrina.

\section{BIBLIOGRAFÍA}

Bon P. y. Maus, D. (2008) Grandes décisions des Cours constitutionnelles européennes. (Paris, Dalloz).

BöCKENFÖRDE, E.W. (2000). Le droit, l'Etat et la Constitution démocratique (textos traducidos y comentados por O. Jouanjan), (Bruselas-París, Bruylant-LGDJ), pp. 235 ss.

Di MANno, T. (1997). Le juge constitutionnel et la technique des décisions interprétatives en France et en Italie, (Paris, Economica-PUAM).

Favoreu, L. (1986). "La décision de constitutionnalité", RIDC,

GenEvoIs, B. (2006). "L'inspiration réciproque des jurisprudences des juridictions suprêmes nationales et internationales en matière de droits fondamentaux", en Diversité des systèmes juridiques et inspiration réciproque des juges, Actes du colloque du Cercle France-Amériques du 24 octobre 2006, Cycle Attractivité économique du droit, LPA 2008, $\mathrm{n}^{\circ} 112$.

Häberle, P. (1994). "El concepto de derechos fundamentales", en Problemas actuales de los derechos fundamentales, (Madrid, Universidad Carlos III de Madrid, Ed. José María Sauca), , pp. 109 s.

Maus, D. (2009). "Le recours aux précédents étrangers et le dialogue des Cours constitutionnelles", Comunicación en la Conferencia Mundial de Justicia Constitucional, Le Cap, 22-24 de enero de 2009.

Mathieu, B. Machelon, J.-P. Mélin-Soucramanien, F. Rousseau D. et Philippe, X. (2009). Les grandes délibérations du Conseil constitutionnel, (Paris, Dalloz).

Melin-Soucramanien, F. (dir.). (2005). L'interprétation constitutionnelle, (Paris, Dalloz).

Ponthoreau, M.-C. (2005). “Le recours aux 'l'argument de droit comparé' par le juge constitutionnel-Quelques problèmes théoriques et techniques”, en F. Melin-Soucramanien (dir.). L'interprétation constitutionnelle, (Paris, Dalloz).

Ponthoreau, M.-C., "La droit comparé en question(s) -Entre pragmatisme et outil épistémologique", RIDC 1/2005,

Slaughter, A.-M. (2003). "A global Community of Courts", Harvard International Law Journal 44/2003

49 A.-M. SLAUGHTER, "A global Community of Courts", Harvard International Law Journal 44/2003, p. 201. 


\section{Sentencias del Consejo Constitucional}

Dossier documental establecido por el Consejo Constitucional

- Sentencia n ${ }^{\circ}$ 59-2 DC de 17, 18 y 24 de junio de 1959, Reglamento de la Asamblea Nacional.

- Sentencia $n^{\circ}$ 74-54 DC de 15 de enero de 1975 . Ley relativa a la interrupción voluntaria del embarazo.

- Sentencia n 83-165 DC de 20 de enero de 1984. Ley de la enseñanza superior.

- Sentencia $\mathrm{n}^{\circ}$ 96-377 DC de 16 de julio de 1996.

- Sentencia $n^{\circ}$ 2001-446 DC de 27 de junio, Ley relativa a la interrupción voluntaria del embarazo y a la contracepción.

- Sentencia ${ }^{\circ}$ 2003-489 DC de 29 de diciembre de 2003, Ley de finanzas para 2004.

- Sentencia n ${ }^{\circ}$ 2003-489 DC de 29 de diciembre de 2003.

- Sentencia n ${ }^{\circ}$ 2004-505 DC de 19 de noviembre de 2004.

- Sentencia $n^{\circ}$ 2005-514 DC de 28 de abril de 2005, Ley relativa a la creación del registro internacional francés.

- Sentencia $n^{\circ}$ 2005-530 DC de 29 de diciembre de 2005, Ley de finanzas para 2006.

- Sentencia $n^{\circ}$ 2007-554 CD de 9 de agosto de 2007, Ley que refuerza la lucha contra la recidiva de mayores y menores.

- Sentencia $n^{\circ}$ 2008-562, DC de 21 de febrero de 2008. Ley relativa a la retención de seguridad y a la declaración de irresponsabilidad penal por causa de enfermedad mental. 